\title{
Research on Chinese Traditional Culture Teaching for Thai Students*
}

\author{
Shufan Wang \\ School of International Education \\ Kunming University of Science and Technology \\ Kunming, China 650093
}

\begin{abstract}
Chinese education in Thailand has a long history. Moreover, under the guidance of the "The Belt and Road" strategy in recent years, the number of Thai students studying in China has increased every year. It is an urgent task that how to develop a set of effective cultural teaching programs for Thai students according to Thai cultural characteristics. Starting with the history of Sino-Thai cultural exchange, and relying on the basic point of Sino-Thai cultural identity-Three Kingdoms Romance, this paper takes the Thai students majoring in Chinese international education at the International College of Kunming University of Technology as an example, exploring the teaching system of all-round Chinese culture with the core of novel text.
\end{abstract}

Keywords-Chinese international education; Thai students; culture teaching; Three Kingdoms Romance

\section{INTRODUCTION}

The Chinese language education in Thailand originated from the history of Sino-Thai exchanges, while the early history of Sino-Thai exchanges was, first of all, a history of economic and trade exchanges. Trade exchanges do not require a high level of cultural knowledge of Chinese, so few native Thais, especially scholars, learn Chinese because they have Chinese-literate people everywhere. In order to trade with China smoothly, the Thai dynasty only encouraged the Chinese to be officials and as accompanying translators. At first, most of Chinese immigrants were poor people, and they were not literate by themselves. But over time, the Taihua people have degraded to the point of being able to use and memorize simple living terms. Therefore, strengthening Chinese language education has become a top priority for Thai Chinese. They began to attach importance to their children's Chinese education. And they hope that their children will be educated in traditional Chinese culture. Therefore, they send their children to study in China, and hire Chinese-literate teachers to teach Chinese at home. This is the starting point of Chinese language education in Thailand. But at this time the quality of study and the level of teachers are often unsatisfactory. Chinese teaching is unsystematic, primitive and rough.

*The key research project of the Yunnan Provincial Committee of the Zhi Gong Party in 2017, The Investigation of Main Problems in the SinoThai Cultural Identity in the "One Belt, One Road" Grand Strategy.

[Chinese Library Classification Number] H19.
Chinese education in the real sense of scale began in the nineteenth century. Thailand began to study western countries, set up special language schools and hired qualified Chinese as teachers. Several Chinese schools in Bangkok, Xin Min School, Jin De School, Ming De School, Pei Yuan School and Yu Min School, were all established by the overseas Chinese Guild in China.[1] Today, Thailand also retains many schools named after overseas Chinese, all funded by local Chinese organizations. There are three levels of Chinese education in Thailand: At the first level, Chinese majors in universities and Confucius Institutes in Thai universities are the most formal and authoritative schools to teach Chinese. At the second level, local overseas Chinese schools, from primary school to high school, teach Chinese, and some even require students to communicate with each other in Chinese on a daily basis, such as the Wu Wen University overseas Chinese School. At the third level, there are some specialized language training institutions and highschool vocational schools offering Chinese majors, such as Chinese tour guides. Although there are so many schools offering Chinese teaching, due to the lack of teachers, the school can provide only basic conversational teaching, which does not form a systematic cultural teaching model. The teaching materials chosen by the school are single, teachers can only teach according to the prescribed textbooks, and no special cultural courses are offered. The lack of teachers and the single type of teaching have seriously affected the development of Thai Chinese language education, and the Chinese language education in Thailand needs to be reformed and innovated.

Thailand is one of the countries with more Chinese in Southeast Asia. And Chinese education began in the 18th century. After long-term development, it has formed a complete Chinese education system from primary school to university. According to statistics from the Office of the Basic Education Committee of the Ministry of Education of Thailand, there were about 110 primary schools, 50 secondary schools and 21 universities offering Chinese language courses in Thailand in 2003. In 2004, there were 32,413 general secondary schools in Thailand and 3,330 private primary and secondary schools. The number of schools offering Chinese language courses accounted for only two-thousandths of this figure. By 2005, there were more than 200 primary and secondary schools offering Chinese courses. In 2007, Chinese has become the second 
largest foreign language for Thais. There are about 340,000 Thais studying Chinese in various schools. If you add people learning by self-study and tutoring, it is far more than 500,000. The number of schools offering Chinese language courses increased to 1,000 in early 2008. The Thai government requires all schools to offer Chinese classes, and by the end of the year it has exceeded 2,000. People' $\mathrm{s}$ Daily reported in 2016 that there are more than 3,000 schools in Thailand offering Chinese language courses, more than 800,000 people are learning Chinese, and China and Thailand have also established 12 Confucius Institutes and 11 Confucius Classes. At the request of the Ministry of Education of Thailand, the Chinese National Office of Han sent 1,284 Chinese language teacher volunteers to Thailand this year, giving the 570 local teachers in Thailand the full amount of scholarship training in China. Sino-Thai Chinese teaching cooperation has become a bright spot in the friendly exchanges between the two countries.

The key to the reform and innovation of Chinese language education in Thailand lies in the realization of cultural identity. Culture is the foundation, approach and attribution of language education. Mr. Ji Xianlin once said: "It is difficult to learn a language without history, culture, social customs, etc. of a country. This is the basic principle of learning a language. Anyone who studies foreign languages must combine language with cultural learning."[2] From this point of view, learning the language of a country must involve the cultural history of the country. Failure to understand the culture of the foreign language country you are learning will inevitably lead to a lack of smooth communication and even a gap.

Language learning is occasionally mechanical repetition and practice, which inevitably makes students feel tedious, and timely cultural introduction must arise students' interest. In order to make class teaching more efficient, it is necessary to grasp the interests of students. Language teaching must be linked to cultural teaching, otherwise class teaching is difficult. Therefore, if a systematic cultural course is established, it will inevitably increase students' interest in learning Chinese and reduce their fear of it. The class for teaching Chinese as a foreign language is not only a place to teach language, but also a platform to promote Chinese culture. After students have basic communicative skills, the cultural curriculum of the learning system not only enhances the students' language skills, but also has a further understanding of Chinese culture. In terms of the longlasting influence of the "Three Kingdoms" in Thailand, the Three Kingdoms culture has become the basis of Sino-Thai cultural identity. On the basis of this, systematic cultural teaching can not only let students know about a new "Three Kingdoms", but also enable students to understand the essence of Confucian culture in the story of the Three Kingdoms. Let students truly understand China and understand Chinese culture and become the messenger of Sino-Thai cultural exchanges.

In the class of Chinese as a foreign language, the systematic introduction of the Three Kingdoms culture is a new research pilot and an innovative experiment on the Chinese language classroom. In the cultural teaching, with the "Three Kingdoms" culture as the core, the teaching contents covering the history of China, the history of Chinese philosophy, the history of Chinese literature, are successfully introduced into the class of Chinese as a foreign language. Then other unique cultural monographs can also "walk in" the classroom of Chinese as a foreign language through this way. Based on real teaching practice, providing a first-hand teaching plan for the culture of Thai students is the problem to be solved in this paper. The culture teaching in the classes of Chinese as a foreign language can be roughly divided into two types: One, teaching Chinese as a foreign language, that is, the cultural teaching in the learning of beginners' language courses; second, the cultural teaching class, which is a cultural special course for middle and senior students. There are essential differences between language classes and cultural teaching courses with different teaching objects and learning qualities. The focus of language courses is to develop the communicative competence of language, and to focus on the skills of listening, speaking, reading, writing, and the use of language. Although the introduction of the cultural background will inevitably be interspersed in the teaching process, it is not the main focus of the language course. Therefore, the materials of the "Three Kingdoms" are introduced into the classroom of the Chinese as a foreign language. The students must have basic communication skills, and the Chinese proficiency is intermediate and advanced. It can also be applied to foreign students in the Chinese language and literature major. The teaching practice is 15 Thai students studying in China (4 boys and 11 girls). Eight of them ( 2 boys and 6 girls) are from Chiang Mai, Thailand, graduated from Chiang Ma's high school. They are studying undergraduate major of Chinese International Education. Before going to the courses learning, they have learned Chinese for one year. Seven students ( 2 boys and 5 girls) are from the Chinese Department of the Ubon Ratchathani Royal University in Bangkok. They have studied Chinese for one to two years in Thailand and continue to study in the third and fourth grades of undergraduate studies in China. And their major is Chinese International Education. The curriculum plan for the training program of Chinese international education majors, the history of ancient Chinese literature is the basic course of disciplines, and 256 studying hours last for one academic year. Students know little about Chinese culture and literature. The teaching process is very difficult with using traditional teaching methods and traditional teaching. How to improve the teaching effect, consider starting from the "Three Kingdoms" culture, and the "Three Kingdom" as the cultural identity of the teaching of Chinese as a foreign language is the fundamental solution to the problem.

First of all, conduct an investigation of 15 people according to the cultural understanding of the "Three Kingdoms". According to the questionnaire survey of 15 Thai students, most of them know it or watch the "Three Kingdoms" TV series and the novel, and can tell one or two people from three kingdoms. Students who know a lot can also roughly tell the story of the Three Kingdoms, while two people do not know what the Three Kingdoms are. Thai students who have an understanding of the "Three Kingdoms" believe that the "Three Kingdoms" can help 
understand the history of China and learn about ancient Chinese civilization. Second, they like the three-nation era with unique personality and talented people, and want to feel the ambition and ideals of the bloody era. Third, they are attracted by heroes, such as "Zhuge Liang of smart", "Liu Bei of kindness ", "Cao Cao of respecting the talented people", "Xi Shi of beautiful appearance". The three main reasons are to stay at the story level of the Three Kingdoms. They do not have an in-depth understanding of the culture of the Three Kingdoms, and there have been errors in confusing people, such as "Diao Chan" and "Xi Shi".

Secondly, the investigation of Chinese traditional culture study by international students. At present, two courses related to Chinese culture are offered for international students: 1. Overview of China, one semester of study time, 32 hours of class; 2. Overview of Chinese culture (using teaching materials), study time of one semester, 32 hours of class. These textbooks are only a rough introduction to Chinese history, culture, politics, economy, and human geography. The content is tedious, the clues overlap and the teacher's teaching focus cannot be highlighted. Students also find it difficult to master when they study, and it is inevitable that they feel distressed, and their enthusiasm and enthusiasm are greatly reduced. Many students still have no knowledge of traditional Chinese culture after completing two courses, and the teaching effect is not obvious.

Therefore, based on the cultural identity of the "Three Kingdoms" between China and Thailand, the introduction of the ancient Chinese literature in the cultural theme of the "Three Kingdoms" will be a reform and innovation attempt for the teaching of Chinese traditional culture and classical literature for Thai students. The curriculum is divided into three parts: first, historical explanation; second, the interpretation of traditional cultural thoughts; third, the introduction of classical literature.

\section{THE HistORY OF THE "THREE KINGDOMS" IS EXPLAINED}

First, in the screening of teaching content, mainly in the "Three Kingdoms" period as the core, including the pre-Qin and Han dynasties, and the Western Jin Dynasty by Si Ma's father and son, and generalized the history of Chinese ancient and medieval history, revealing the changes of the Chinese feudal dynasty.

It explains the history in accordance with the chronological order of The Three Kingdoms Romance, taking Luo Guanzhong's story of the Three Kingdoms as the main line, and modifying the classical vernacular text to the oysters modern text as the students' main textbook, with the reference of Chen Shou's "Three Kingdoms". The story of "Three Kingdoms" only talks about the major events on the timeline, and we must give a brief explanation of the characters appearing in the "Three Kingdoms." The textbooks used in this topic can draw on film and television materials or simple text materials to highlight the causes, development, climax and end of the Three Kingdoms. Advancing the introduction of common sense of classical culture, such as understanding the "Spring and Autumn Zhan
States", "hundreds of philosophers", "Qin Shihuang", "The struggling of Chu and Han ", "Han Wu Emperor", "outside officials interference", "Three Kingdoms" And other historical facts. Because the Spring, Autumn and Zhan Period to the Three Kingdoms Period, it was the formation of Chinese classical idioms. The focus was on historical facts to realize the idiom teaching of Chinese culture.

Historical explanation is the basic enlightenment stage of all culture teaching. At this stage, attention should be paid to stimulating students' interest in Chinese culture. Therefore, the main teaching method at this stage is multimedia film and television teaching method. The specific recommended film and television include "Da Qin Empire", "Yu Dan's Analects / Zhuangzi's Experience", "Han Wu Emperor", "The Three Kingdoms Romance" and so on.

\section{THE INTERPRETATION OF TRADITIONAL CULTURAL} THOUGHTS

\section{A. The Core Idea of the "Three Kingdoms" - Confucian of Benevolence, Respecting "Liu" and Belittling "Cao"}

The formation of the "Three Kingdoms" phenomenon, which has continued for a hundred years in Thailand, relies on the Chinese classical literary works The Three Kingdoms Romance. Therefore, the teaching of Chinese traditional culture relies mainly on the text of the novel. "The Three Kingdoms Romance" is a historical romance novel based on the Western Jin historian Chen Shou's "Three Kingdoms", written by the Ming Dynasty Luo Guanzhong. Therefore, there are many fictional story-lines in the book, exaggerated or even distorted in the setting of characters. The most prominent is the ideological tendency of "supporting Liu and suppressing Cao" embodied in the book. Explain the source of the ideological tendency of "supporting Liu and suppressing Cao" in the "Three Kingdoms", and it is necessary to introduce the interpretation of Confucian "benevolence". "The Three Kingdoms Romance" chose Shu as the main description of the country, not only because Liu Bei was born in the Han Dynasty royal family, but more he met the standards of the "benevolence" in the hearts of the people.

The core of Confucius's thoughts is "benevolence", and the two are "benevolence" referring to the relationship between people. Confucius's thoughts are rooted in the real society. What is solved is the first attribute of human beings as a social person and the social problem. Therefore, the Confucian doctrine is social ethics. "The Analects of Confucius and Yan Yuan" records that Fan Chi asked "Benevolence", and Confucius said: "The benevolent loved everyone" and "self-respecting is benevolent. One day, people can be self-denial and reunion, the world will return to the benevolence." "The Analects of Confucius and Wei Ling": "Confucius said: benevolent people don't harm the benevolence for survival, and make prepare to kill themselves to achieve benevolence" whose core refers to mutual dearness between people and Confucius as the highest moral standard. But in fact, the meaning of "benevolence" lies in the establishment of an ethical and moral relationship in feudalism, which in turn is a feudal 
hierarchy. Liu Bei is the blood of the Han Dynasty, so from the birth, he has legitimacy and orthodoxy. The development of Confucianism to Mencius put forward the idea of "benevolence politics", that is, "the people are valuable, the society is second, the king is light" and those who implement "benevolent government" are "good emperors". Each story has a protagonist, who conforms to the aesthetics of the people and the moral values of the Confucian tradition, who is the embodiment of the true, beautiful integrating the good things. For a long time, Mendacious view of the ideal society of "the valuable people and the light nobles" has made Chinese intellectuals infinitely respect, and the broad masses of the people infinite. The so-called "benevolence" can get the people's heart, and the people who win the hearts of the people have the world. Liu Bei's character and behavior are just in line with this standard. Liu Bei's character in the Three Kingdoms is weak and not violent, who often solve problems euphemistically. There has been rumors that Liu Bei built his country by crying, which is not an exaggeration. It means that Liu Bei has a sad and sorrowful feeling of

"benevolence" .In "The Three Kingdoms Romance", Liu Bei's image is based on "benevolence" and widely applies benevolent government.

On the contrary, chaotic thieves are hated, abused and killed by mass people. The typical villain of the Three Kingdoms, Cao Cao, who was created by the author in The Three Kingdoms Romance, is in stark contrast to Liu Bei. In the author's pen, Cao Cao is "the governor of the world, the traitor of the chaos." The typical case of "The Three Kingdoms Romance", Cao Cao killed wrongly eight people of Lv Boshe's family who treated him fervidly and ran away. On the way, Cao Cao encountered Lu Boshe, fearing his revenge, and then slashing him, and issued: "I would rather let me lose the world, and I will call the world to bear me." Cao Cao attacked power and made good use of his strategy. Although Mao Zonggang commented on "The Three Kingdoms Romance", "If Cao Cao wants to apply for a military order, he can also borrow it. When he borrowed it, the more he used it, the more magical it is, he is the first traitor". Mao thought that Cao Cao is hypocritical. However, the "cutting the first generation" has been commonplace in ancient times. Cao Cao's actions show the tactical wisdom of politicians. Therefore, Mao Zonggang repeatedly sighed: "The power is cute! The power is cute!" He also affirmed Cao's ability to operate as a politician.

\section{B. Confucian Moral and Ethical Norms - Taking "Three Outlines and Five Permanents", with "Righteousness" as the First}

"Three Outlines" is a set of feudal ethics system: "the Emperor is the minister's outline, the husband is the wife's outline, and the father is the son's outline". More meaningful is the "five permanents": "benevolence, righteousness, courtesy, wisdom, and faith." The "five permanents", also known as "five relationships", refers to the basic five relationships between people and the specifics of the three classes. Although the "three outlines and five permanents" are feudal ethics, it plays a positive role in shaping the character of the Chinese nation: For example, they attaching importance to subjective willpower, focusing on integrity, morality, self-restraint, and determination, and emphasizing human social responsibility and historical mission, have played a positive role. The main government of "benevolence" is to first stand with kindness and Liu Bei did it. The typical act of "giving up Xuzhou three times" leaves readers a deep impression. Liu Bei did what Confucius said, "The benevolent person, who wants to stand up and reach up to others, does not want to do it to others." ("The Analects of Confucius") standing for the noble moral standard of "benevolence".

Talking about "righteousness", in the "Three Kingdoms", there is a representative figure, Guan $\mathrm{Yu}$. This artistic image is more deeply rooted in the hearts than Liu Bei, Cao Cao, Sun Quan and even Zhu Geliang. Because not everyone can become a monarch to give "benevolence", then there must be another norm to constrain the conduct between people, this is "righteousness", which solves the ethical norms of ordinary people. It is an important ethical category of Confucianism, whose original intention is benevolence and justice. As early as in "Book of Rites, Songs": "Morality and benevolence could not exist without righteousness." Mencius in the Zhan period also emphasized this concept; afterwards, Dong Zhongshu in Han Dynasty inherited it and regarded "benevolence and justice" as the highest traditional morality. After the Song Dynasty, due to admiration of philosophers, "benevolence and righteousness" became an alias of traditional morality, and often regarded "morality, benevolence, wisdom, and trust" as "five permanents". If "benevolence" is the foundation of the Lord, then "righteousness" is the courtier, the foundation of ordinary people. Therefore, the Chinese people say that "benevolence and righteousness" are two-way. The upper-level ruler's way from top to bottom is "benevolence"; the fundamental way for ordinary people to communicate horizontally is "righteousness." Therefore, Guan Yu has a wide market and believers throughout the Confucian cultural circle in China and Thailand.

The interpretation of Confucianism-based traditional cultural thoughts is the key difficulty in the whole course and the key to deepening and upgrading the curriculum. In this part, the Confucian culture is emphasized with the support of the Analects. The cross-explanation of the remarks in the 20 Analects and the story of The Three Kingdoms Romance is based on the interpretation and the understanding of the character's character in the Analects.

\section{THE INTRODUCTION OF CLASSICAL LITERATURE}

The introduction of classical literature is the process of the story-to-literature improvement of The Three Kingdoms Romance, and it is also the difficulty of the entire teaching process. In this stage, the class focuses on the core figure of The Three Kingdoms Romance, Cao Cao's literary, military, political, and historical achievements, revealing the truth of "respecting Liu and disparaging Cao", restoring historical truth, and interpreting the first part of Chinese history. The famous writers of the Wei and Jin Dynasties in the "Three Kingdoms" appeared. The story in the book led to the wonderful life experiences and major literary contributions 
of San Cao, Seven Genius, Zhuge Liang, Cai Wei and Cai Yan.

\section{Wei Jin Literature Course Design}

\section{A. Overview}

The Wei, Jin, Southern and Northern Dynasties literature refers to the phenomenon of literary development from the first year of Jianan in the Eastern Han Dynasty (196) to the emperor Yang Jianchen (589). It was a period of Chinese literature in the Middle Ages. The story of "Three Kingdoms" occurred from 190 to 280 AD. In the history of literature, this period was called Jian'an Literature Period. The characteristics of literature in this period can further deepen the understanding of students, if combined with the historical stories of the "Three Kingdoms".

From the Dong Han Dynasty, Dong Zhuo's chaos to the north general unification (the 13th year of Jian'an) is the pioneering period of Jian'an style. The poetry is sad and generous, and the content is mostly recorded in the late Han Dynasty, represented by Cao Cao. From the 14th year to the 25 th year of Jian'an, it is the development period of Jian'an style. The poetry is full of magnificence, and there are many banquets, princes, and military works, represented by Cao Pi. From the 25th year of Jian'an to the early years of Wei Emperor, it was the end of Jian'an style. The poetry is profound, emotional and elegant, and the content is mostly useless, grievances and generosity, represented by Cao Zhi.

\section{B. Jian'an Spirit}

The Jian'an spirit is also called Jian'an strength, Han Wei strength or Jian'an character. "Character" refers to the ideological content of the work, and "Strength" refers to the artistic form of the work. It mainly refers to the true content of the poetry creation from the Jian'an of the late Han Dynasty to the early Wei Emperor, with the sincere feelings, the generous and sad sentiments, and the fresh language . It is strong, ideological and artistic, and it is characterized by perfection and unity. "Jian'an sprit" is a generalization of people's aesthetic style during the Jian'an period. The so-called Jian'an spirit is an artistic style formed by the combination of the inner anger and appeal of the work and the simple and healthy combination of language expression. During the Jian'an period, due to the turmoil in the society, the political enthusiasm of the literati was generally high. Therefore, most of their poetry and poetry creations were characterized by rich content, rich feelings, generosity and succinct features, and a clear and artistic style. The strength, the enriched ideological content, the infectious emotions and the perfect combination and the fresh in the language are the basic connotations of Jian'an style.

\section{Cao Cao}

1) Cao Cao's life and leading thoughts: Cao Cao, a famous politician, strategist and writer in the Three Kingdoms period, under the situation of sharp class contradictions at that time, he actually integrated a series of progressive measures such as merging and strengthening, developing squatting, and soliciting talented people to strengthen his own strength and unify the north. He attaches great importance to literature. "It is a must for ascending, and creating new poems."("Three Kingdoms: Wei Zhi") said that Cao Cao can be "the emperor's respect, elegant poetry", and "external martial arts, internal prosperity literature". On the one hand, Cao Cao relied on his political leadership position to collect talents extensively, resulting in the Jian'an literature situation of " bettering and prosperous". On the other hand, Cao Cao created a new literary style with his own creative works, and was the pioneer of the new situation of Jian'an literature. He plays a role in the history of literature: one is his role in creating and providing a good creative environment and conditions; the other is his role in creating and practicing. If there is no Cao Cao's soliciting, there would not be group of people below. If there is no unified North of Cao Cao, there would not be social order gradually stable, and the literati would not be able to obtain a lower and stable creative environment. Without the thought of $\mathrm{Cao} \mathrm{Cao}$, the liberation and attention to literati and literature, the silent situation of poetry creation cannot be completely broken. Without Cao Cao borrowing the old inscriptions from Yuefu to create a new generation of poetry style, there will be no new literary situation in Jian'an Literature.

Cao Cao's dominant thought is the return to the primitive Confucian humanistic spirit. The greatest value of Cao Cao's poetry lies: it breaks through the shackles of the two Han dynasties, and profoundly poeticizes the basic spirit of primitive Confucianism, which marks the rational consciousness of the Chinese nation. The awakening of the original Confucianism is transformed into a magnificent poem with the artistic charm of moving the world and feeling the ghosts. The primitive Confucianists believed that scholars and gentlemen must possess two spiritual styles, one is the consciousness of the world, and the other is the sense of urgency. Cao Cao's poetry is the artistic reproduction of these two spiritual styles.

2) Cao Cao's literature achievements: Cao Cao's literary achievements are mainly reflected in poetry. There are more than 20 in his poems, without a large number, but the achievements are outstanding. Poetry can be broadly divided into four categories: chronicles, narrations, immortals, and history. However, the general history of literature has divided his poetry into two categories:

- Reflecting the chaos of the times and the hardships of people's livelihood

His masterpieces are "Hao Li Lane", "Zhu Lu Lane", "The East and West Lane", "Bitter Cold Lane".

These poems are very realistic, with desolate and sorrowful feelings. The author has inherited a fine tradition. It truly describes the sufferings and wars of the late Han Dynasty, and profoundly reflects the characteristics of the era of the wind and the evil. Cao Cao's poems showing "the time is chaos, the song is a slogan", full of "sexuality, and discipline", truly reflects the individual's career, experience 
and feelings. Through these poems, we have recorded many important aspects of social life for decades. The content has a historical basis and is extremely credible.

- Expressing the poet's political ideals and ambitions of contributions

These masterpieces are "Short Songs", "Hao Li Lane", and "Turtles".

These poems not only have the portrayal life experience of the author, but also the eagerness of recruiting talents for the realization of the great cause of reunification, as well as his political ideals. In short, Cao Cao's poetry is closely related to his personal life experience to reflect his time, most of which have written the reality and have a strong authenticity. Reading his poems is like reading a concise history of the late Han Dynasty, the events of the rise and fall, and full of vividness.

\section{CONCLUSION}

Through the introduction of the cultural curriculum, students' attention to the "Three Kingdoms Culture" is placed on the historical fact, and it is different from the previous simple attention to the story. The students tried to read, write and recite Cao Cao's poems, and they had a new understanding of $\mathrm{Cao} \mathrm{Cao}$ and restored the history. Most students can get the main point of view from this lesson. The real $\mathrm{Cao} \mathrm{Cao}$ is a famous politician, strategist and writer in the Three Kingdoms period. Cao Cao's thought is the return of the primitive Confucian humanistic spirit. The value of Cao Cao's poetry lies in the profound poetry of the basic spirit of primitive Confucianism. Learning Cao Cao's poetry can fully understand the essence of traditional Confucian culture.

Afterwards, the students were provoked a strong interest, and they began to read the Thai version of the "Three Kingdoms" and watch the Chinese version of the TV series "The Romance of the Three Kingdoms". Students with better Chinese learning began to read "The Romance of the Three Kingdoms". The success of the Three Kingdoms culture was introduced into the class of Chinese culture teaching. This time, the desired teaching effect was achieved. Taking this as an example, future cultural topics will be introduced into the culture class teaching. In addition to enriching students' learning, they can expand the knowledge of students and lay a good cultural background for them to learn Chinese better.

\section{REFERENCES}

[1] Yang Zuowei. The Past, Present and Future of Chinese Education in Thailand [J]. Southeast Asian Studies, 2003 (5): 73.

[2] Ji Xianlin. Language Learning and Cultural Learning Must Be Combined. [J] Chinese Foreign Languages, 2005 (6): 1.

[3] Yu Dingbang, Chen Shusen. History of Sino-Thai Relations [M]. Beijing: Zhonghua Book Company, 2009.

[4] Shi Ronghua. History of Sino-Thai Cultural Exchange [M]. Kunming: Yunnan Fine Arts Publishing House, 1997.

[5] Luan Wenhua. History of Thai Literature [M]. Beijing: Social Sciences Academic Press, 1998. 